\title{
Differential characteristics of incobotulinumtoxinA and its use in the management of glabellar frown lines
}

This article was published in the following Dove Press journal:

Clinical Pharmacology:Advances and Applications

II March 2013

Number of times this article has been viewed

\section{Welf Prager}

Dermatologikum Hamburg, Hamburg, Germany
Correspondence: Welf Prager

Dermatologikum, Stephansplatz 5, 20354 Hamburg, Germany

Tel +494035I0 757I

Fax +494035107510

Email prager@dermatologikum.de
Objectives: This review examines the pharmacologic and clinical characteristics of incobotulinumtoxinA (Xeomin ${ }^{\circledR} /$ Xeomeen $^{\circledR} /$ Bocouture $^{\circledR} /$ XEOMIN Cosmetic ${ }^{\mathrm{TM}}$; botulinum toxin type A [150 kDa]), which is free from complexing proteins, and discusses its efficacy and safety in the treatment of glabellar frown lines. Differences between incobotulinumtoxinA and other commercially available botulinum neurotoxin type A (BoNT/A) products that have been approved by the European Medicines Agency, US Food and Drug Administration, and other regulatory agencies for this indication are also discussed.

Findings: IncobotulinumtoxinA differs from other commercially available BoNT/A preparations, in that it is free from complexing proteins and contains only active neurotoxin, minimizing foreign protein load. IncobotulinumtoxinA is commonly used at a 1:1 dose ratio with onabotulinumtoxinA and displays comparable efficacy and safety; furthermore, it is associated with early onset and long duration of effect, and high levels of subject satisfaction. In terms of practical considerations, incobotulinumtoxinA does not require cold storage and demonstrates low spread, enabling precise treatment and good tolerability.

Conclusion: IncobotulinumtoxinA is an efficacious and well-tolerated treatment for glabellar frown lines. It differs from other BoNT/A preparations, in that it is free from complexing proteins and contains only active neurotoxin, which is relevant clinically, as this reduces the foreign protein load and minimizes the risk of neutralizing antibody production. In practical terms, incobotulinumtoxinA has a long shelf-life, remaining stable without the need for refrigeration, and due to its limited spread is a precise localized treatment.

Keywords: clinical use, glabellar frown lines, incobotulinumtoxinA, pharmacology, complexing proteins

\section{Introduction}

Facial aging is a multifactorial process that is attributed to a combination of soft tissue atrophy, bone resorption and remodeling, muscular hypertrophy, and muscle imbalances. ${ }^{1,2}$ These facial changes are the result of intrinsic damage caused by genetics and hormonal and biochemical changes, and extrinsic damage related to a number of environmental factors, including gravity, smoking, and sun damage. ${ }^{2,3}$ In addition, the appearance of the face as it ages is also a direct result of the emotional expressions exhibited by the individual. The repeated display of emotions by the habitual use of specific facial muscles will eventually result in the appearance of hyperfunctional facial lines, which may give an erroneous and negative impression of emotions or personality characteristics. ${ }^{4}$

During the fourth decade of life, several visible signs of aging begin to appear in the periorbital region, including eyelid laxity and glabellar furrows. In addition, gradual 
descent of the eyebrow gives the appearance of smaller eyes. These changes become more pronounced as aging continues, and glabellar lines, along with other facial wrinkles and folds, remain noticeable and ingrained on the face even when the individual is in repose, instead of being dynamic and present only when communicating emotion., ${ }^{2,4}$ Horizontal glabellar furrows are produced by the repeated action of the procerus muscle, whereas vertical kinetic lines and folds appear in the glabellar region due to repetitive activity of the corrugator superciliaris muscles, which originate from the medial end of the superciliary arch and extend out into the deep surface of the skin above the middle of the orbital arch. Along with the procerus and obicularis oculi muscles, the corrugator is responsible for the inferomedial pull of the eyebrows, giving rise to the expression of negative emotions such as anger and anxiety (Figure 1). ${ }^{2,5}$ As well as giving the unintentional impression of negative emotional states, the persistent presence of glabellar frown lines can be suggestive of an older than actual age, affecting an individual's self-perception, emotional well-being, and perception by others. ${ }^{4,6}$ This perceived unwelcome characteristic of aging can have a considerable negative impact on an individual's mood state and, for some individuals, could even contribute to the onset of depression. A single treatment with botulinum neurotoxin type A (BoNT/A) may reduce the symptoms of major depression. ${ }^{7}$

\section{Overview of current strategies for the management of glabellar frown lines \\ Available treatment procedures}

The goal of treatment is to reduce the appearance of glabellar frown lines that suggest negative emotions such as anger or stress, but still allow an adequate degree of emotional expressivity. Methods of addressing glabellar frown lines consist of surgical interventions such as wire subscison, ${ }^{8}$ forehead lifting, ${ }^{9,10}$ and the application of silicone implants. ${ }^{11}$ However, invasive surgical techniques are associated with prolonged recuperation times, ${ }^{12}$ potential complications, and adverse effects. ${ }^{13}$ Furthermore, surgery can be an extremely risky option for individuals merely seeking easily assessable cosmetic solutions. For these subjects, and for those who are precluded from, or contraindicated for, surgery, the availability of minimally invasive treatments such as dermal filling agents (eg, hyaluronic acid) and percutaneous selective radiofrequency nerve ablation ${ }^{14-18}$ has increased the number of treatment options for this indication. Nonetheless, the current nonsurgical treatments for prominent glabellar frown lines may have limitations, as most merely address symptoms and do not treat the origin of the wrinkle by correcting the defective underlying musculature. Although temporary plumping of facial lines can be achieved with fat implants, as with other fillers that are placed subdermally, this may be associated with possible vascular occlusion leading to infarction or embolic damage to the retina or optic nerve, which, in rare cases, can result in blindness. ${ }^{5,19,20}$ Intradermal treatment is therefore preferred in order to avoid intravascular injection, although fat injections are now widely considered to be obsolete in this indication.

The use of botulinum neurotoxins produced by the various strains of the anaerobic bacterium Clostridium botulinum for the improvement of glabellar kinetic folds was first reported by Carruthers and Carruthers ${ }^{13}$ in 1992. Paralysis of the central brow musculature (corrugator, procerus, and medial orbicularis), and the subsequent unopposed action of the medial elevators of the brow, eliminated the presence

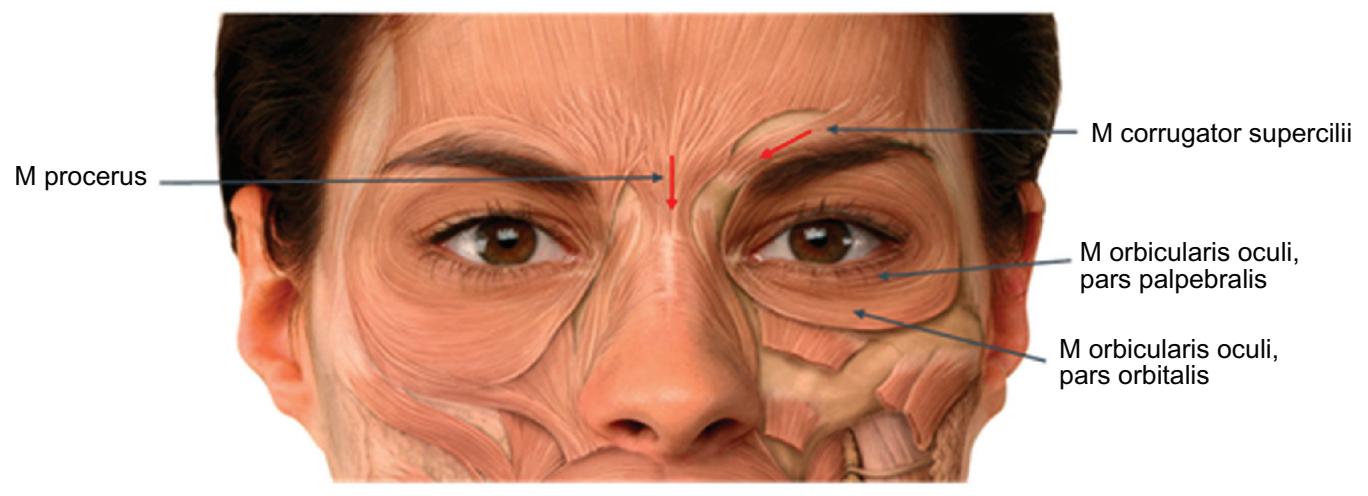

$\longrightarrow$ Direction of pull of the muscles

Figure I Muscles involved in glabellar frown lines. Reproduced with permission from Merz Pharmaceuticals GmbH. 
of lines in the glabellar region and caused a temporary medial brow lift. ${ }^{5,21}$ Treatment of the procerus is not always necessary and need be injected only if there is evidence of depressor activity. ${ }^{22}$ With its advantages including a rapid onset of aesthetic results, and quick and straightforward application, ${ }^{5,23,24}$ BoNT/A has since become the cornerstone of minimally invasive aesthetic facial procedures, and its use for the cosmetic treatment of glabellar frown lines is well documented. In addition, BoNT/A injections are frequently combined with volumizing treatments, such as injectable fillers, soft tissue augmentation, contouring procedures, including light-based and laser-based resurfacing, and chemical peels, to boost outcomes and create a multifaceted, "whole face" approach to facial rejuvenation. ${ }^{15,25,26}$ It is recommended that initial treatment should be performed using BoNT/A alone in order to assess the need for any further treatment of residual issues, such as static lines and deep folds. If these problems persist, combination treatment with hyaluronic acid fillers can be undertaken at the next session. ${ }^{15}$ In the author's experience, injecting in two sessions can help to avoid complications.

Incobotulinumtoxin $A\left(\right.$ Xeomin $^{\circledR} /$ Xeomeen $^{\circledR} /$ Bocouture $^{\circledR} /$ XEOMIN Cosmetic ${ }^{\mathrm{TM}}$; botulinum toxin type A [150 kDa]; Merz Pharmaceuticals GmbH, Frankfurt am Main, Germany), a BoNT/A preparation that is free from complexing proteins, is licensed in the US, Canada, Germany, the UK, all other major European countries, and South Korea for the treatment of glabellar frown lines, as well as in Russia, Mexico, and Argentina for the treatment of mimic wrinkles and hyperkinetic facial lines, respectively. Two other BoNT/A preparations have been approved by the US Food and Drug Administration for glabellar frown lines: onabotulinumtoxinA (Botox Cosmetic ${ }^{\circledR} /$ Vistabel $^{\circledR}$; Allergan, Irvine, CA) and abobotulinumtoxinA (Dysport ${ }^{\circledR}$; Ipsen Ltd, Slough, Berkshire, UK/Azzalure ${ }^{\circledR}$; Galderma UK Ltd, Watford, Hertfordshire, UK).

\section{Administration of BoNT/A for glabellar frown lines}

A summary of the manufacturers' recommendations for the administration of each of the three approved BoNT/A preparations for the treatment of glabellar frown lines is provided in Table 1.

\section{Reconstitution}

Before application of BoNT/A for the treatment of glabellar frown lines, reconstitution must be performed in accordance with good clinical practice guidelines, particularly in respect of asepsis. For incobotulinumtoxinA and onabotulinumtoxinA, the manufacturers recommend that 50 unit $(\mathrm{U})$ vials are reconstituted prior to use in $1.25 \mathrm{~mL}$ of unpreserved sodium chloride $9 \mathrm{mg} / \mathrm{mL}(0.9 \%)$ solution for injection, corresponding to an active substance concentration of $4 \mathrm{U}$ per $0.1 \mathrm{~mL} .^{24,27}$ For abobotulinumtoxinA, 125 Speywood $\mathrm{U}$ vials should be reconstituted using $0.63 \mathrm{~mL}$ of sodium chloride $(0.9 \%)$ solution for injection, which provides $125 \mathrm{U}$ of active substance at a concentration of $10 \mathrm{U}$ per $0.05 \mathrm{~mL}$ of reconstituted solution. The accurate measurement of $0.63 \mathrm{~mL}$ can be achieved using $1 \mathrm{~mL}$ insulin-type syringes provided by the manufacturer. ${ }^{27}$ However, in practice, physicians often use their own preferred volume for reconstitution. ${ }^{28}$

It is debatable whether dilution of BoNT/A preparations has any effect on clinical efficacy, duration, and neurotoxin spread. ${ }^{29}$ Higher dilutions are thought by some to be associated with a greater risk of spread to nontargeted facial muscles, poor clinical results, and shorter duration of treatment effect. ${ }^{30-33}$ However, this belief is not shared by all practitioners who use BoNT/A for cosmetic indications. ${ }^{34}$ The question of whether the degree of dilution has any impact on efficacy was investigated in a study by Prager et al, ${ }^{35}$ in which $100 \mathrm{U}$ incobotulinumtoxinA were diluted in $2.5 \mathrm{~mL}$ (Group A) or $4 \mathrm{~mL}$ (Group B) sodium chloride solution before administration of $25 \mathrm{U}$ to 40 subjects with moderateto-severe glabellar frown lines. No significant differences in efficacy were seen between the two concentrations. Response rates for Group A versus Group B after 2 weeks, 3 months, and 4 months were $100 \%$ versus $89.5 \%, 84.2 \%$ versus $64.7 \%$, and $53.3 \%$ versus $61.5 \%$, respectively. Similar efficacy results were reported in other studies investigating onabotulinumtoxinA for glabellar frown lines; ${ }^{31,36}$ however, these studies also reported that higher dilutions of onabotulinumtoxinA were associated with increased discomfort during administration (as larger volumes of the preparation need to be injected $)^{36}$ and a higher incidence of eyelid ptosis. ${ }^{31}$

\section{Administration}

Prior to injection, some physicians treat the injection area with an antiseptic, ${ }^{21}$ and the author always uses an alcoholfree disinfectant; however, this is not included in the manufacturer's instructions for onabotulinumtoxinA and incobotulinumtoxin $\mathrm{A} .{ }^{24,37}$ The instructions for abobotulinumtoxinA recommend the removal of any makeup and disinfection of the skin with a local antiseptic. ${ }^{27}$ In general, anesthesia (eg, topical cream) is not necessary prior to injecting BoNT/A, but cooling with ice may be useful. Of a panel of experts who convened to develop consensus guidelines 
Table I Use of botulinum neurotoxin type A products for the treatment of glabellar frown lines: manufacturer's recommendations ${ }^{24,27,37}$

\begin{tabular}{llll}
\hline Manufacturer's recommendations & IncobotulinumtoxinA & OnabotulinumtoxinA & AbobotulinumtoxinA \\
\hline Dose for glabellar frown lines & $20 \mathrm{U}$ & $20 \mathrm{U}$ & $50 \mathrm{U}$ \\
Number of injection sites & 5 & 5 & 5 \\
Volume administered per injection site & $0.1 \mathrm{~mL}(4 \mathrm{U})$ & $0.1 \mathrm{~mL}(4 \mathrm{U})$ & $0.05 \mathrm{~mL}(10 \mathrm{U})$ \\
Needle size & $30 \mathrm{G}$ needle & $30 \mathrm{G}$ needle & $29-30 \mathrm{G}$ needle \\
Minimum treatment interval & 3 months & 3 months & 3 months \\
\hline
\end{tabular}

on the use of BoNT/A in facial aesthetics, $65 \%$ agreed that use of a topical anesthetic, including ice, was beneficial in some subjects. ${ }^{38}$ The treated area should not be massaged, and $78 \%$ of the panel members recommended that subjects should contract the injected muscles repeatedly for 90 minutes to 2 hours after treatment in an effort to expedite toxin uptake. ${ }^{38}$

Generally, a five-injection approach is taken, with the total dose of BoNT/A divided equally between five sites in the glabellar region. ${ }^{5,24,27,37,39}$ The subject is first asked to frown, in order to allow easy location of the specific muscles. Once identified, the subject is asked to relax prior to the injection. ${ }^{5}$ One injection is administered to the procerus muscle, followed by one injection on each side of the face in the central part of the corrugator muscles, $1 \mathrm{~cm}$ above the bony orbital rim. Lastly, one injection is administered on each side in the lateral part of the corrugator muscles, $1 \mathrm{~cm}$ above the bony orbital rim (Figure 2). ${ }^{24,39}$ For male subjects, an additional injection may be performed on each side into the orbicularis, just above the eyebrow in the mid-pupillary line. ${ }^{5}$ Before

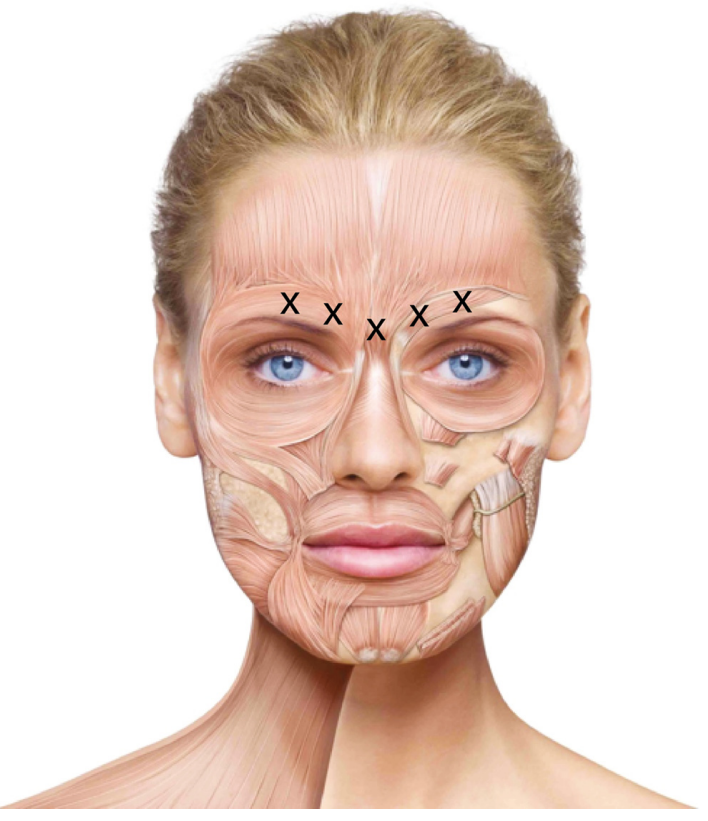

Figure 2 Injection sites for treatment of glabellar frown lines. Reproduced with permission from Merz Pharmaceuticals $\mathrm{GmbH}$. and during the injection, the thumb and index finger should be used to apply firm pressure below the edge of the eye socket in order to prevent diffusion of the solution in this region. Superior and medial alignment of the needle should be maintained during the injection. ${ }^{24,37}$ For all three products, intramuscular injections should be performed using a sterile, thin (29-30 gauge) needle. . $^{24,27}$

In order to achieve optimal results, tailoring the injection sites and doses to the subject's anatomy is important. This was highlighted by a recent study that classified different patterns of glabellar frown lines, allowing the most important muscles involved in each pattern to be identified. This information allows a subject's treatment to be optimized for their facial variations, with heavily used muscles receiving a larger dose or more injections, and lesser-used muscles receiving less to achieve a more natural look. ${ }^{40}$

\section{Dosing}

The recommended standard total dose of $20 \mathrm{U}$ of incobotulinumtoxinA for the treatment of glabellar frown lines, constituting a total injection volume of $0.5 \mathrm{~mL}$, is divided equally and administered intramuscularly into each of the aforementioned five injection sites $(0.1 \mathrm{~mL}$ per injection site; equivalent to $4 \mathrm{U}$ incobotulinumtoxinA) according to the European label. ${ }^{24}$ The same standard dosing recommendations apply to onabotulinumtoxinA (European label). ${ }^{37}$ For abobotulinumtoxinA, a total dose of $50 \mathrm{U}$ is recommended ( $0.25 \mathrm{~mL}$ of reconstituted solution) and divided between the five injection sites $(0.05 \mathrm{~mL}$ per injection site; equivalent to $10 \mathrm{U}$ abobotulinumtoxinA). ${ }^{27}$ According to the European label for abobotulinumtoxinA, in the event of treatment failure or diminished effect, no dose increase is recommended and alternative treatment methods should be employed. ${ }^{27}$ For incobotulinumtoxinA, the dose can be increased to $30 \mathrm{U}$ depending on the individual's needs. If there is no treatment effect 1 month after injection, and the lack of effect is deemed to be due to insufficient dosage, then the dose can be adjusted and applied following a 3-month treatment interval. ${ }^{24}$ With onabotulinumtoxinA, if the standard $20 \mathrm{U}$ dose does not result in significant improvement from baseline 1 month 
after injection and the cause is thought to be insufficient dosage, then, according to the manufacturers, the dose can be increased to $40 \mathrm{U}$ or $50 \mathrm{U}$, provided a 3-month treatment interval is observed. ${ }^{37}$

For most subjects, $20 \mathrm{U}$ of incobotulinumtoxinA or onabotulinumtoxin $\mathrm{A}$ is an appropriate starting dose and is commonly used in clinical trials..$^{6,39,41-44}$ Clinical studies in subjects with glabellar frown lines have shown that there is no difference in efficacy between $20 \mathrm{U}$ and $30 \mathrm{U}$ doses of BoNT/A, ${ }^{45,46}$ and a recent study showed that a dose of onabotulinumtoxinA equivalent to $30 \mathrm{U}$ was nonsuperior to a dose of incobotulinumtoxinA equivalent to $20 \mathrm{U}^{22}$ These findings demonstrate that a single dose of $20 \mathrm{U}$ is appropriate in the majority of cases, and a greater effect cannot be achieved by increasing the dose. This conclusion has also been supported by the recent study by Moers-Carpi et al, ${ }^{47}$ and by the head-to-head study that demonstrates similar efficacy when incobotulinumtoxin $\mathrm{A}$ and onabotulinumtoxin $\mathrm{A}$ are applied using a 1:1 unit conversion ratio. ${ }^{48}$ However, higher doses can be appropriate for subjects, usually men, who tend to have a larger muscle mass, ${ }^{28}$ and consensus guidelines for the treatment of glabellar frown lines emphasize the need to individualize treatment, recommending onabotulinumtoxinA dose ranges of 10-30 U for women and 20-40 U for men for glabellar frown lines. ${ }^{15}$

\section{Pharmacology of incobotulinumtoxinA compared with other BoNT/A preparations}

There are a number of pharmacologic differences between incobotulinumtoxinA and the other commercially available BoNT/A preparations. Table 2 provides a summary of the different formulations and the manufacturing characteristics.

\section{Mode of action and pharmacokinetics}

Pharmacologically, BoNT/A acts by blocking cholinergic neuromuscular transmission or cholinergic autonomic innervation of exocrine glands and smooth muscles by inhibiting the action of the soluble N-ethylmaleimide sensitive factor attachment protein receptor protein, SNAP-25, which is involved in fusion of acetylcholine-containing synaptic vesicles with the plasma membrane. ${ }^{49-51}$ The action of BoNT/A therefore inhibits the release of acetylcholine, resulting in nonresponse of the neuromuscular junction to nerve impulses (chemical denervation). The mechanism of action by which BoNT/A exerts its effects on cholinergic nerve terminals comprises four sequential steps: (1) the binding of the heavy chain of BoNT/A to glycolipids and the protein receptor SV2 on cholinergic terminals; (2) internalization of the toxin into the nerve terminal by endocytosis; (3) translocation of the neurotoxin's light chain into the cytosol of the nerve terminal; (4) and cleavage of SNAP-25 by the light chain, causing inhibition of acetylcholine release. ${ }^{49-52}$ The effect of BoNT/A at the neuromuscular junction is only temporary, as the effect is terminated by the development of sprouts forming new synapses, which subsequently degenerate as the soluble N-ethylmaleimide sensitive factor attachment protein receptor protein complex is restored in the original nerve terminal. ${ }^{49,50}$ The effect of BoNT/A usually starts to decline after about 2.5 months. ${ }^{49}$ Internalized BoNT/A is degraded intracellularly, and any freely circulating BoNT/A molecules are phagocytosed or pinocytosed and degraded. ${ }^{24}$

Table 2 Summary of characteristics of botulinum neurotoxin type A products used in the treatment of glabellar frown lines $24,27,37,57,60,61,91$

\begin{tabular}{|c|c|c|c|}
\hline & $\begin{array}{l}\text { IncobotulinumtoxinA } \\
\left.\text { (Xeomin }^{\otimes / B o c o u t u r e}{ }^{\circledR}\right)\end{array}$ & $\begin{array}{l}\text { OnabotulinumtoxinA } \\
\text { (Botox }^{\circledR} / \text { Vistabel }^{\circledR} \text { ) }\end{array}$ & $\begin{array}{l}\text { AbobotulinumtoxinA } \\
\text { (Dysport }^{\circledR} / \text { Azzalure }^{\circledR} \text { ) }\end{array}$ \\
\hline Manufacturer & Merz Pharmaceuticals GmbH & Allergan Inc & Ipsen Inc/Medicis Inc \\
\hline Molecular mass $(\mathrm{kDa})$ & 150 & 900 & $500-700$ \\
\hline Complexing proteins & No & Yes & Yes \\
\hline $\begin{array}{l}\text { Mean maximal area of anhidrosis in the } \\
\text { forehead area }\end{array}$ & $364.3 \pm 138.1 \mathrm{~mm}^{2}($ per $5 \mathrm{U})$ & $343 . \mathrm{I} \pm \mathrm{I} 10.7 \mathrm{~mm}^{2}(\operatorname{per} 5 \mathrm{U})$ & $\begin{array}{l}459.1 \pm 151.8 \mathrm{~mm}^{2}(\mathrm{per} \\
12.5 \mathrm{U})\end{array}$ \\
\hline Units/vial & $100 / 50$ & $100 / 50$ & $500 / 300$ \\
\hline Mean amount of neurotoxin per 100 units & $0.44 \mathrm{ng}(\mathrm{CV}=1.9 \%)$ & $0.73 \mathrm{ng}(\mathrm{CV}=3.5 \%)$ & $0.65 \mathrm{ng}(\mathrm{CV}=\mathrm{II} .4 \%)$ \\
\hline Specific neurotoxin potency & $227 \mathrm{U} / \mathrm{ng}$ & $137 \mathrm{U} / \mathrm{ng}$ & $154 \mathrm{U} / \mathrm{ng}$ \\
\hline IncobotulinumtoxinA:unit conversion ratio & I:I & $\mathrm{I}: \mathrm{I}$ & $\mathrm{I}: 2.5-3$ \\
\hline Dosage & $20 \mathrm{U}$ & $20 \mathrm{U}$ & $50 \mathrm{U}$ \\
\hline Shelf-life & 3 years & 3 years & 2 years \\
\hline Storage & $\begin{array}{l}\text { Up to } 25^{\circ} \mathrm{C} \text { (no refrigeration } \\
\text { required) }\end{array}$ & $\begin{array}{l}2^{\circ} \mathrm{C}-8^{\circ} \mathrm{C} \text { (refrigeration } \\
\text { required) }\end{array}$ & $\begin{array}{l}2^{\circ} \mathrm{C}-8^{\circ} \mathrm{C} \text { (refrigeration } \\
\text { required) }\end{array}$ \\
\hline
\end{tabular}

Abbreviation: $\mathrm{CV}$, coefficient variant. 
It is not possible to perform classic pharmacokinetic and distribution studies of BoNT/A, because such small quantities (picograms per injection) of the active substance are applied and it rapidly and irreversibly binds to cholinergic nerve terminals. ${ }^{24}$

\section{Complexing proteins}

The most notable difference between incobotulinumtoxinA and the other two BoNT/A preparations is that incobotulinumtoxinA is specifically purified and is thus free from complexing proteins. Native botulinum toxin is a high-molecular-weight complex (900 kDa or smaller) in which the neurotoxin $(150 \mathrm{kDa})$ is noncovalently attached to additional nontoxic proteins (hemagglutinin and nonhemagglutinin clostridial proteins). ${ }^{53,54}$ During the manufacturing process for incobotulinumtoxinA, these complexing proteins are separated and discarded from the neurotoxin during a number of purification steps. The resulting active ingredient of incobotulinumtoxinA represents the pure neurotoxin $(150 \mathrm{kDa})$ that is free from complexing proteins..$^{24,54}$

The biologically active component of the high-molecularweight complex is the $150 \mathrm{kDa}$ neurotoxin, ${ }^{54}$ and the complexing proteins do not appear to contribute to the therapeutic effect of BoNT/A treatment. ${ }^{55}$ Furthermore, recent investigations have determined that complexing proteins in BoNT/A preparations have no beneficial role and do not appear to affect the spread of the toxin from the injection site..$^{56,57}$ A study by Eisele et $\mathrm{al}^{58}$ determined that rapid dissociation of the BoNT/A complexes in onabotulinumtoxinA and abobotulinumtoxinA occurs at neutral to basic $\mathrm{pH}$ values, with up to $80 \%$ of the neurotoxin being released within 1 minute once this $\mathrm{pH}$ threshold is achieved. The presence of complexing proteins had previously been thought to protect the neurotoxin from harsh environmental conditions (eg, low intragastral $\mathrm{pH}$ after oral ingestion); ${ }^{59}$ however, in real-time and accelerated stability studies, incobotulinumtoxinA was found to be stable without refrigeration for 48 months and was not affected by short-term temperature stress up to $60^{\circ} \mathrm{C}$, demonstrating that complexing proteins are not required for product stability. ${ }^{60}$

\section{Active/inactive neurotoxin}

A recent study investigating the amount of BoNT/A protein found in incobotulinumtoxinA, onabotulinumtoxin $\mathrm{A}$, and abobotulinumtoxinA revealed that, in addition to containing only the neurotoxin without extraneous clostridial proteins, incobotulinumtoxinA is likely to contain only active neurotoxin; in contrast, onabotulinumtoxinA is likely to contain additional denatured/inactive neurotoxin, possibly due to the use of sodium chloride, which seems to be detrimental for activity during the drying process. ${ }^{61}$ The results suggest that an increased percentage of denatured/ inactivated neurotoxin, approximately $60 \%$, is delivered with onabotulinumtoxinA compared with incobotulinumtoxinA when the same dosage is applied to achieve the same clinical effect. Because denatured/inactive protein cannot contribute to the clinical effect, it merely represents an unnecessary additional foreign protein load. A higher dose of antigen may increase the risk of formation of neutralizing antibodies and lead to therapy failure, as discussed here. ${ }^{61}$

\section{Immunogenicity}

As botulinum toxins consist of foreign proteins, there is a possibility that development of antibodies against the neurotoxin may occur. The presence of nontoxic complexing proteins in onabotulinumtoxinA and abobotulinumtoxinA represents an additional foreign protein load, which may increase the potential for eliciting an immune response. ${ }^{62}$ The formation of neutralizing antibodies against the toxin blocks the action of BoNT/A, resulting in partial or total antibody-induced therapy failure. ${ }^{33,49}$

The use of onabotulinumtoxinA and abobotulinumtoxinA for aesthetic purposes may result in the development of antibodies and treatment resistance. ${ }^{63-66}$ Preclinical studies have shown that, in contrast to onabotulinumtoxinA and abobotulinumtoxinA, incobotulinumtoxinA did not lead to the production of neutralizing antibodies following repeated injections into New Zealand white rabbits. ${ }^{55,67}$ The preclinical results suggest that the risk of antibody formation is lower for incobotulinumtoxinA compared with other formulations that contain complexing proteins, a conclusion also drawn from a review of the data on the use of incobotulinumtoxinA in focal dystonias. ${ }^{68}$ An ongoing study of incobotulinumtoxinA for cervical dystonia in treatment-naïve patients and those who had received prior treatment with other BoNT/A formulations showed no development of neutralizing antibodies following continuous treatment with incobotulinumtoxinA during the first 2 years of the study ${ }^{69}$ In addition, a reduction in the amount of clostridial protein per $100 \mathrm{U}$ vial of a BoNT/A preparation led to a decrease in the number of nonresponders ${ }^{70}$ and the risk of antibody formation, ${ }^{71}$ indicating a relationship between a lower clostridial protein content of BoNT/A preparations and a lower risk of neutralizing antibody formation. 


\section{Neurotoxin potency}

In the aforementioned study by Frevert ${ }^{61}$ in vitro biochemical assays were performed to determine the overall mean concentration of the $150 \mathrm{kDa}$ neurotoxin present in incobotulinumtoxinA, onabotulinumtoxinA, and abobotulinumtoxinA; these results were then used to calculate the specific neurotoxin potency (defined as the potency or biologic activity [units] per mass of neurotoxin protein [ng]) of these preparations. IncobotulinumtoxinA was found to contain a mean concentration of neurotoxin $(0.44 \mathrm{ng}$ per $100 \mathrm{U}$ vial) and thus the highest specific neurotoxin potency $(227 \mathrm{U} / \mathrm{ng})$, followed by abobotulinumtoxinA (0.65 ng per $100 \mathrm{U} ; 154 \mathrm{U} / \mathrm{ng}$ ) and, lastly, onabotulinumtoxinA ( 0.73 ng per $100 \mathrm{U}$ vial; $137 \mathrm{U} / \mathrm{ng}$ ) (Figure 3 ). Given that the clostridial protein content per $100 \mathrm{U}$ for onabotulinumtoxin $\mathrm{A}$ is $5 \mathrm{ng}^{61}$ and for abobotulinumtoxinA is $0.87 \mathrm{ng},{ }^{72}$ the specific biologic potencies relative to total foreign protein are $20 \mathrm{U} / \mathrm{ng}$ and $115 \mathrm{U} / \mathrm{ng}$, respectively, compared with $227 \mathrm{U} / \mathrm{ng}$ for incobotulinumtoxinA.

Although differences in neurotoxin-specific activity between the BoNT/A preparations were seen in the Frevert study, other assay procedures can be used to determine biologic activity. In another recent study, the neurotoxin potency of incobotulinumtoxinA and onabotulinumtoxinA was measured using a standardized $\mathrm{LD}_{50}$ mouse assay and the same dilution factor between doses for each product. No statistically significant difference in potency was detected between these BoNT/A preparations. ${ }^{73}$ The biologic potencies were well within the range of 100 mouse $\mathrm{U}+25 \%,-20 \%$ as stipulated by the European Pharmacopoeia; the mean potency of onabotulinumtoxinA (in mouse $\mathrm{U} \pm$ standard deviation) was $103.1 \pm 6.5$, whereas that for incobotulinumtoxinA was $101.7 \pm 6.2$. The conclusion was that onabotulinumtoxin $\mathrm{A}$ and incobotulinumtoxinA can be compared using a 1:1 conversion ratio, allowing easy exchange of both products in the standard aesthetic clinical setting. ${ }^{73}$

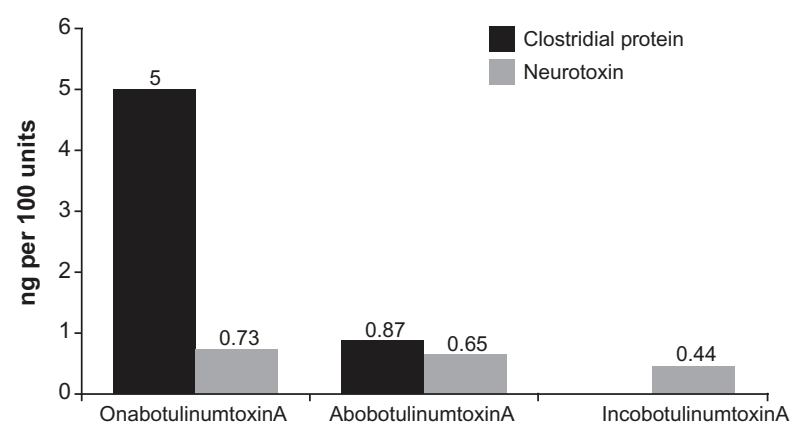

Figure 3 Amount of clostridial protein and neurotoxin per $100 \mathrm{U}$ of incobotulinumtoxin $\mathrm{A}$, onabotulinumtoxin $\mathrm{A}$, and abobotulinumtoxin $\mathrm{A}$. $37,61,72$
This finding is supported by a clinical trial showing that, when administered at the same dose, incobotulinumtoxinA is noninferior to onabotulinumtoxinA for the treatment of glabellar frown lines. ${ }^{74}$

\section{Toxin spread and area of efficacy}

The precise localization of BoNT/A during treatment of glabellar frown lines is imperative to prevent spread of the neurotoxin to (and subsequent paralysis of) nearby untargeted muscles, as this can lead to adverse events such as eyelid ptosis. ${ }^{5,57}$ Consequently, the toxin spread of BoNT/A preparations is of important clinical relevance, particularly when selecting the most appropriate treatment. ${ }^{57}$ A number of studies have been conducted to assess the area of efficacy of BoNT/A preparations..$^{57,75-77}$ As inhibition of acetylcholine release by these agents inhibits endocrine glands, resulting in the cessation of sweating, the area of anhidrosis that is produced gives an indication of the area of spread. Consequently, studies that assess toxin spread are based on the hypothesis that the size of the anhidrotic area correlates with the size of the area of reduced muscle action and clinical effect. One recent study compared the spread of incobotulinumtoxinA ( $5 \mathrm{U}$ ) versus onabotulinumtoxinA (5 U) and abobotulinumtoxinA (12.5 U) at a 1:1:2.5 dose conversion ratio. ${ }^{57}$ At 6 weeks after injection of each agent in an identical volume $(0.125 \mathrm{~mL})$ into the forehead of 29 subjects, the size of the anhidrotic halos (ie, mean maximal area of anhidrosis) was found to be comparable between incobotulinumtoxin $\mathrm{A}$ and onabotulinumtoxin $\mathrm{A}$ $\left(364.3 \pm 138.1 \mathrm{~mm}^{2}\right.$ vs $343.1 \pm 110.7 \mathrm{~mm}^{2}$, respectively). However, the maximal area of anhidrosis observed with abobotulinumtoxinA $\left(459.1 \pm 151.8 \mathrm{~mm}^{2}\right)$ was larger than that of incobotulinumtoxinA. When the spread of each agent over time was assessed, the area under the effect curve over 6 months for incobotulinumtoxinA was again comparable with that of onabotulinumtoxinA and smaller than that of abobotulinumtoxinA. These results showed that incobotulinumtoxinA has a similar spread to that of onabotulinumtoxinA and a smaller one than abobotulinumtoxinA, also indicating that the presence of complexing proteins does not affect toxin spread. ${ }^{57}$ This finding is not surprising, given that dissociation of protein complexes is rapid at physiologic $\mathrm{pH} .{ }^{58}$ As the authors of this study highlight, for treatment of glabellar frown lines a total dose of $20 \mathrm{U}$ incobotulinumtoxinA and onabotulinumtoxinA is recommended by their respective manufacturers, compared with a dose of $50 \mathrm{U}$ recommended by the manufacturer of abobotulinumtoxinA. The dose of abobotulinumtoxinA 
appears to result in a wider spread than that of the other two agents and therefore has the potential to cause an increased risk of side effects due to migration into adjacent nontarget muscles. ${ }^{57}$

\section{Clinical use and efficacy, safety, and tolerability of incobotulinumtoxinA Phase III clinical trials}

\section{Randomized placebo-controlled trials}

A number of Phase III placebo-controlled trials of incobotulinumtoxinA have been conducted, with consistently favorable results. In two recent identically designed, randomized, double-blind, placebo-controlled, Phase III studies, subjects ( $\geq 18$ years of age) with moderate-to-severe glabellar frown lines (score of 2 or 3 ) on the 4-point facial wrinkle scale (FWS), assessed at maximum frown, were treated with a single injection of $20 \mathrm{U}$ incobotulinumtoxinA or placebo for a period of 120 days. $^{42,43}$ A total of 547 subjects were enrolled across these two Phase III studies, and efficacy was assessed using the new, rigorous composite endpoint of treatment success (CETS), reflecting the Food and Drug Administration's interest in identifying substantial improvements after treatment. Responders were defined as those with a $\geq 2$-point improvement compared with baseline at maximum frown at Day 30 by the investigator's rating on the FWS and by the subject's assessment on a 4-point scale. Therefore, a subject was a responder only if both criteria were fulfilled. In both studies, treatment with a single dose of incobotulinumtoxinA was found to be superior to placebo $(P<0.0001)$, according to the CETS $\left(60.3 \%\right.$ vs $0.0 \%{ }^{42}$ $47.8 \%$ vs $0.0 \%){ }^{43}$ The individual components of the CETS also demonstrated superiority of incobotulinumtoxinA over placebo in both studies. Investigator assessment on the FWS at maximum frown at Day 30 revealed a $\geq 2$-point improvement compared with baseline in $76.6 \%{ }^{42}$ and $70.9 \%{ }^{43}$ of subjects in the incobotulinumtoxinA groups compared with $0.0 \%$ in the placebo groups in each study $(P<0.0001$ for both comparisons).

Results for secondary endpoints (reduction in investigatorrated score to "none" [0] or "mild" [1], and a reduction from baseline of at least 1 point in severity rating), which were based on the previously accepted standards for assessing treatment efficacy, confirmed the primary endpoint findings. Defining a treatment response as a composite of both an investigatorassessed $\geq 2$-point improvement from baseline on the FWS and a subject-assessed 4-point scale, allows for a more robust definition of a responder. Because only subjects fulfilling both of these two criteria were considered responders on the CETS, these new assessments represent the most stringent applied to date in placebo-controlled studies of BoNT/A for treatment of glabellar frown lines. ${ }^{42,43}$

In both trials, the incidence of adverse events (AEs) deemed to be related to incobotulinumtoxinA treatment was low $\left(7.1 \%{ }^{42} 12.1 \%{ }^{43}\right)$, with headache being the most commonly reported $\mathrm{AE}(3.8 \%$ and $7.1 \%$ in each study, respectively). Overall, serious AEs were experienced by three subjects receiving incobotulinumtoxinA; one of these led to discontinuation of treatment but was not treatment related. The development of neutralizing antibodies was not observed in any subject treated with incobotulinumtoxinA.

\section{Head-to-head trials}

Sattler et $\mathrm{al}^{74}$ reported results from a much anticipated large, Phase III, rater- and subject-blind, noninferiority study of incobotulinumtoxinA and onabotulinumtoxinA. A total of 381 women (aged 18-50 years) with moderate-to-severe glabellar frown lines were randomized in a 3:1 ratio to receive $24 \mathrm{U}$ incobotulinumtoxinA or $24 \mathrm{U}$ onabotulinumtoxinA, respectively. The $24 \mathrm{U}$ dose was chosen, as it was the average dose used by physicians for the treatment of glabellar frown lines in clinical practice. High response rates (response defined as an improvement of $\geq 1$ point on the FWS) of $96.4 \%$ and $95.7 \%$ at maximum frown were seen at 4 weeks post injection in the incobotulinumtoxinA and onabotulinumtoxinA groups, respectively, and remained high at 12 weeks $(80.1 \%$ in the incobotulinumtoxin A group and $78.5 \%$ in the onabotulinumtoxinA group). Statistical analysis confirmed noninferiority of incobotulinumtoxinA to onabotulinumtoxinA at both time points. Although lower rates were seen at rest, results were still comparable between the two treatment groups. Consistently high responses were also seen on the subject selfassessment of treatment using the FWS (response defined as an improvement of $\geq 1$ point compared with baseline), with $93.9 \%$ of the subjects treated with incobotulinumtoxin A versus $93.5 \%$ of those treated with onabotulinumtoxinA showing a response at Week 4 at maximum frown. Similarly, when using the Patient's Global Assessment (PGA) of change in appearance of glabellar frown lines compared with the situation immediately before injection, $93.5 \%$ of the subjects in the incobotulinumtoxinA group and $92.5 \%$ of subjects in the onabotulinumtoxinA group were responders (defined as those with a score of at least +2 points) at Week 4 , again confirming noninferiority of incobotulinumtoxinA to onabotulinumtoxinA. Comparable results for tolerability were also seen, with $3.2 \%$ and $5.2 \%$ of subjects experiencing treatment-emergent AEs related to treatment in the incobotulinumtoxinA and 
onabotulinumtoxinA groups, respectively. For both treatments, headache was the most commonly reported treatment-related AE (1.8\% vs $2.1 \%$, respectively). One case of eyelid ptosis was reported in the onabotulinumtoxinA group, which later resolved. Neutralizing antibodies to either treatment were not observed.

The purpose of noninferiority trials is to evaluate whether a new treatment is no worse than an existing active comparator by a specified margin called the equivalence margin. Any improvement seen with the new treatment still lies within the definition of noninferiority ${ }^{78}$ therefore, the conclusion of noninferiority does not rule out possible superiority of the new treatment. ${ }^{79}$

A double-blind, randomized trial was conducted by Rappl et al, ${ }^{80}$ in which 120 subjects with mild-to-severe glabellar frown lines were treated with $21 \mathrm{U}$ incobotulinumtoxinA, $21 \mathrm{U}$ onabotulinumtoxinA, or $63 \mathrm{U}$ abobotulinumtoxinA. This study assessed the onset and duration of efficacy of these three products; the findings are discussed in a later section.

\section{Open-label trials}

A recent prospective, open-label, Phase III, singlearm study was conducted to determine the efficacy of incobotulinumtoxinA for the treatment of glabellar frown lines. ${ }^{39}$ A total of 105 subjects (aged 18-65 years) with moderate-to-severe glabellar frown lines at maximum frown, on the FWS, were treated with $20 \mathrm{U}$ incobotulinumtoxinA, divided between five injection sites, and assessed over 84 days. A high proportion of responders (defined as subjects with an improvement of $\geq 1$ on the FWS when compared with Day 0 ) were observed at 28 days (98.1\%) and 84 days (80.0\%) post injection. Additionally, subjects also rated treatment success highly, with $98.1 \%$ and $85.6 \%$ of subjects achieving a score of at least +2 points on the PGA, on Days 28 and 84 , respectively. In this study, incobotulinumtoxinA demonstrated favorable tolerability, with only $3.8 \%$ of subjects experiencing a treatment-emergent $\mathrm{AE}$ that was deemed related to treatment. The development of neutralizing antibodies against incobotulinumtoxinA was not observed. ${ }^{39}$

The long-term efficacy of incobotulinumtoxinA was evaluated by Rzany et $\mathrm{al}^{44}$ in a prospective, open-label, multicenter, repeat-dosing, Phase III extension trial that recruited subjects from the two Phase III placebo-controlled trials, ${ }^{42,43}$ along with subjects from two other randomized, placebo-controlled trials. ${ }^{81,82}$ A total of 801 subjects with moderate-to-severe glabellar frown lines on the FWS at baseline received up to eight cycles of incobotulinumtoxinA treatment in a period not exceeding 2 years; the treatment interval was at least 85 days. Response rates (defined as subjects with glabellar line severity of none [0] or mild [1] at maximum frown on the FWS) were high and remained high for up to eight treatment cycles, ranging from $79.1 \%$ to $89.6 \%$. Subject self-assessment of efficacy was also maintained over the cycles of treatment, with response rates (the proportion of subjects with $\geq 1$-point improvement on a 4-point scale compared with Day 0) ranging from $85.9 \%$ to $93.8 \%$. This study demonstrated the long-term efficacy of incobotulinumtoxinA and also showed that repeat dosing is effective, with a trend toward increasing response rates that were consistently high for up to eight regular cycles of treatment. Notably, the incidence of treatment-emergent AEs during this extended period was low. The majority of events reported were mild-to-moderate in nature. No serious AEs related to the study drug were reported and no neutralizing antibodies were detected. ${ }^{44}$ This was the first long-term study that resembles the repeated usage of incobotulinumtoxinA in the clinical setting.

\section{Other clinical trials}

In a study conducted by Schleyer and Berneburg, ${ }^{83}$ ten female subjects were treated with 20-23 U incobotulinumtoxinA in the glabellar region. After 2 weeks, $90 \%$ of subjects responded "well" or "very well" to the treatment. The effect of treatment was sustained in the majority of subjects (89\%) at Week 12. Treatment was well tolerated, with only one case of headache being reported (this resolved on the same day as treatment administration).

\section{Studies investigating the onset and duration of effect of BoNT/A}

Time to onset and duration of effect are important factors that may influence subject satisfaction with cosmetic treatments, as they have an impact on cost and convenience. Results from randomized clinical trials of incobotulinumtoxinA have shown that improvement in the severity of glabellar frown lines is usually observed within 2 to 3 days post treatment, and the maximum effect is seen after 30 days. ${ }^{24,42,43}$ This rapid onset of treatment effect does not appear to be diminished by repeated administration of incobotulinumtoxinA, as demonstrated in the long-term extension study, where onset of effect occurred within the "first few days" after treatment for each of the eight treatment cycles. ${ }^{44}$

Few studies have been conducted to specifically examine the onset and duration of effect of BoNT/A preparations..$^{23,80,84}$ Two recent studies have investigated the 
onset and durability of the effect of incobotulinumtoxinA. ${ }^{80,85}$ In a single-arm, prospective, proof-of-concept study conducted by Prager et al, ${ }^{85}$ glabellar frown lines were treated with $25 \mathrm{U}$ incobotulinumtoxinA in 23 subjects who were assessed over a 5-month period. At 2-4 days after treatment, a high proportion $(95.2 \%)$ of subjects were responders when treatment response was defined as subjects with a $\geq 1$-point improvement on the Merz 5-point scale at maximum frown, compared with baseline. The responder rate, according to this definition, was $100 \%$ for the next three visits until Visit 6 (16-17 weeks post treatment), when it decreased to $94.7 \%$. The persistence of the treatment effect (ie, $\geq 1$-point improvement from baseline) was also evident for up to 5 months following treatment, when over $75 \%$ of subjects were still responders at maximum frown. During this time period, responder rates were higher for glabellar lines at maximum frown than for glabellar lines at rest. When responders were defined as subjects with a $\geq 2$-point improvement on the Merz 5-point scale at maximum frown, $85.0 \%$ of subjects were classed as responders $2-4$ days after treatment; this rate increased to $100 \%$ at Visit 3 (Day $8 \pm 1$ ) and Visit 4 (Day $14 \pm 2$ ), decreasing to $78.9 \%$ at Visit 5 (12-13 weeks post treatment), 50\% at Visit 6 (16-17 weeks post treatment), and $20 \%$ at Visit 7 (20-21 weeks post treatment). For glabellar frown lines at rest, no subjects were responders at any time point using this more stringent definition of response, probably due to the low baseline scores for glabellar frown lines at rest. An early onset of treatment effect was observed in this trial, with $84 \%$ of the maximum effect of incobotulinumtoxinA at maximum frown occurring 2-4 days after injection. In subject self-assessments, $18 \%$ of subjects rated their appearance as younger than their actual age at baseline compared with $73 \%$ at Visit 4 (Day $14 \pm 2$ ) post treatment. Additionally, the majority of subjects rated their glabellar frown lines as "improved" or "markedly improved" compared with baseline at Visits 2 (Day $3 \pm 1$ ), 3 (Day $8 \pm 1$ ), and 4 (Day $14 \pm 2$ ). ${ }^{85}$

In a double-blind randomized study of 120 subjects, Rappl et $\mathrm{al}^{80}$ compared the onset and duration of incobotulinumtoxinA (21 U), onabotulinumtoxinA (21 U), and abobotulinumtoxinA (63 U). IncobotulinumtoxinA had the most rapid onset of effect, with $95 \%$ of subjects achieving an effect on Day 4 compared with only $41 \%$ and $35 \%$ in the onabotulinumtoxinA and abobotulinumtoxinA groups, respectively. Although the longest duration of effect was seen with incobotulinumtoxinA, this was not statistically significant. For incobotulinumtoxinA, 13\% of subjects still showed an effect at Day 180 compared with 3\% and 5\% in the onabotulinumtoxinA and abobotulinumtoxinA groups, respectively.

\section{Dosing of incobotulinumtoxinA in clinical trials}

Units of BoNT/A products are not considered to be interchangeable, ${ }^{24,27,37}$ due to the different assays used by the manufacturers to assess potency and monitor quality. However, a 1:1 dose ratio between incobotulinumtoxinA and onabotulinumtoxinA is often suggested, ${ }^{73,86}$ which would seem appropriate considering the evidence for noninferiority of incobotulinumtoxinA to onabotulinumtoxinA at the same dosage for the treatment of glabellar frown lines. ${ }^{74}$ In addition, a recent meta-analysis of clinical and preclinical data from eleven trials comparing incobotulinumtoxinA and incobotulinumtoxinA concluded that there was no difference in the relative potency of the two products, and that they should continue to be used at a 1:1 dose ratio. ${ }^{87}$

In studies of incobotulinumtoxinA for treatment of glabellar frown lines, the doses investigated have ranged from $20 \mathrm{U}$ (as recommended by the manufacturer) to $24 \mathrm{U}$ (as used in the head-to-head noninferiority study against onabotulinumtoxinA).$^{74}$ There has been some debate regarding whether increasing the dose above the recommended $20 \mathrm{U}$ of either incobotulinumtoxinA or onabotulinumtoxinA for treatment of glabellar frown lines will achieve better results, or if there is a ceiling effect preventing any further improvement of treatment outcomes. ${ }^{22}$ In a split-face study by Prager and Rappl, ${ }^{22}$ which omitted treatment of the procerus muscle, 35 subjects with symmetrical moderate-to-severe glabellar frown lines on the Merz 5-point scale ${ }^{1}$ were treated with either incobotulinumtoxinA or onabotulinumtoxinA using a doseconversion ratio of 1:1.5 (incobotulinumtoinA:onabotulinum toxinA) and assessed for 4-6 months. IncobotulinumtoxinA treatment consisted of two injections of $4 \mathrm{U}$ (equivalent to $20 \mathrm{U}$ when corrugator muscles on both sides and the procerus muscle are treated), whereas onabotulinumtoxinA treatment consisted of two injections of $6 \mathrm{U}$ (equivalent to $30 \mathrm{U}$ in total when corrugator muscles on both sides and the procerus muscle are treated). The split-face design of this study facilitated intraindividual comparison between the two products, due to the ease of identifying any asymmetry, which would indicate a difference in efficacy of the two products. This meant that a smaller number of patients was sufficient to generate statistically significant results. Response rates (defined as $\geq 1$-point improvement from baseline) were the same in both groups throughout the study period (100\% at Week 4, $81 \%$ at Month 4, and 50\% at Month 6). Therefore, nonsuperiority 
of the $50 \%$ higher dose of onabotulinumtoxinA to that of incobotulinumtoxinA was confirmed at 4 weeks, 4 months, and 6 months post treatment.

Although a 1:1 dose ratio for incobotulinumtoxinA:o nabotulinumtoxinA is widely accepted as appropriate, ${ }^{73,86}$ a standardized conversion ratio between incobotulinumtoxin $\mathrm{A}$ or onabotulinumtoxinA and abobotulinumtoxinA has not yet been determined. For therapeutic indications such as cervical dystonia, onabotulinumtoxinA:abobotulinumtoxinA conversion ratios of up to $1: 11$ have been used in the past. ${ }^{88}$ However, more recent evidence suggests that lower conversion ratios (below 1:3) are preferable in clinical dermatology, ${ }^{89}$ and for glabellar frown lines, relative strength of action has been suggested to be 1:2 to 1:4 (onabotulinumtoxinA/incobotulin umtoxinA:abobotulinumtoxinA) ${ }^{86}$

\section{Subject satisfaction and acceptability Subject assessment of treatment outcomes}

The use of subject-assessed treatment outcomes is becoming increasingly common in clinical trials. In trials investigating BoNT/A treatment for glabellar frown lines, subject-reported outcomes help to assess subject satisfaction with their treatment, which is of crucial importance in aesthetics. In clinical trials of incobotulinumtoxinA, subject assessment is often carried out using a 4-point Patient Assessment Scale (PAS), for which subjects respond, at rest, to the question "How would you judge the degree of your glabellar lines by comparison with sample photos at this visit?", with potential rating responses being: $0=$ no visible vertical line(s) at all, $1=$ slightly visible vertical line(s), 2 = moderate vertical line(s) with depression, and 3 = deep vertical line(s) and depression that cannot be effaced by spreading, and, at maximum frown, to the question "How would you judge the potency of frown muscle action by comparison with sample photos at this visit?", with potential rating responses being: $0=$ no muscle action at all, $1=$ some even slight muscle action possible, 2 = moderately strong muscle action possible, and $3=$ strong muscle action possible, which may cause local pallor. ${ }^{43,44}$ In some trials, subject selfassessment has been performed using the 9-point PGA, in response to the question "How would you rate the change in the appearance of your glabellar lines compared with the situation immediately before the injection?". The potential PGA rating responses are: $+4=$ complete improvement, $+3=$ marked improvement, $+2=$ moderate improvement, $+1=$ slight improvement 0 = unchanged,$-1=$ slight worsening, $-2=$ moderate worsening, $-3=$ marked worsening, and $-4=$ very marked worsening. ${ }^{39,74}$ The long-term incobotulinumtoxinA study also included a 6-point Likert-type subject assessment scale to subjectively assess glabellar frown lines, with subjects asked to assess the degree of their glabellar frown lines at maximum frown and at rest using the ratings $0=$ none at all to $5=$ very deep, with intervening grades not having specific descriptions. $^{44}$

\section{Subject satisfaction with incobotulinumtoxinA}

As discussed previously, high levels of subject satisfaction have been reported in clinical trials of incobotulinumtoxinA for glabellar frown lines. In the two randomized Phase III trials, in which a responder on the PAS was defined as a subject with $\geq 1$-point improvement compared with baseline
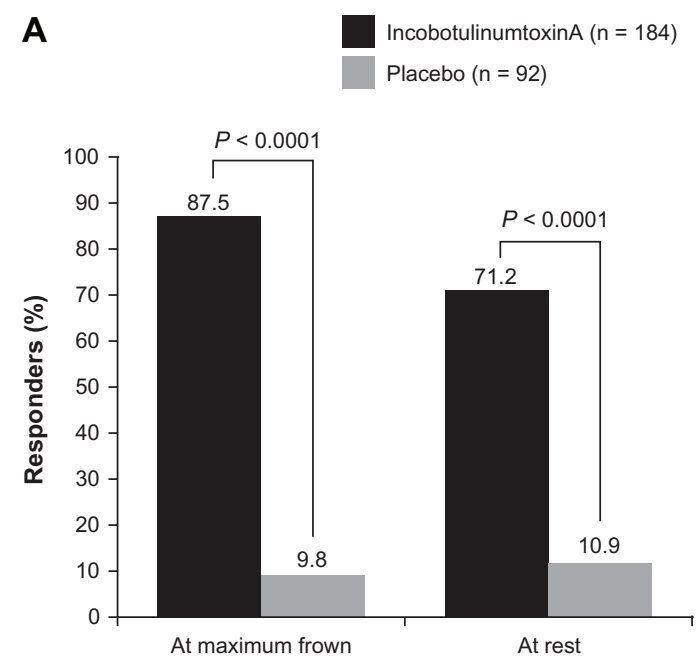

B IncobotulinumtoxinA ( $\mathrm{n}=182)$ Placebo $(n=89)$

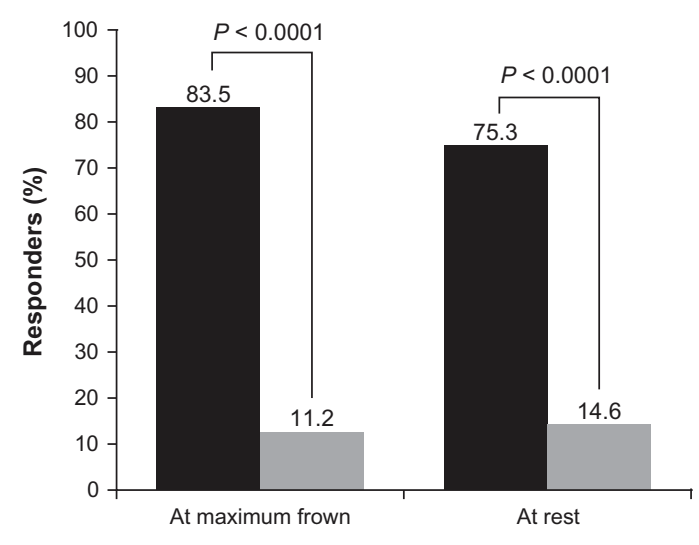

Figure 4 Subject assessment of response with $20 \mathrm{U}$, using a 4-point scale where a responder was defined as a subject with at least a I-point improvement compared with baseline at Day 30 from two Phase III, placebo-controlled trials: (A) Carruthers et al, ${ }^{42}$ full-analysis set; and (B) Hanke et al, ${ }^{43}$ full-analysis set, observed cases. 
at Day 30, high response rates for incobotulinumtoxinA were observed compared with placebo $(P<0.0001)$, both at maximum frown and at rest (Figure 4). ${ }^{42,43}$ In the open-label Phase III trial of incobotulinumtoxinA, 99.0\% and $93.3 \%$ of subjects achieved an improvement of at least 1 scale point compared with Day 0 using the PAS at maximum frown and at rest, respectively. ${ }^{39}$ Similarly high results were seen with the PGA: $98.1 \%$ of subjects were responders (ie, achieved a score of at least +2 points) on Day $28 .{ }^{39}$ Importantly, high subject satisfaction with treatment has been reported for both incobotulinumtoxinA and onabotulinumtoxinA, with response rates on the PGA of $93.5 \%$ for incobotulinumtoxinA and $92.5 \%$ for onabotulinumtoxinA at Week $4 .{ }^{74}$ Subject satisfaction with incobotulinumtoxinA treatment appears to be sustained in the long term, as demonstrated in the study by Rzany et al, ${ }^{44}$ where results on the PAS (subjects with a $\geq 1$-point improvement) were maintained over eight cycles of treatment (range from $85.9 \%$ to $93.8 \%$ at maximum frown and from $67.0 \%$ to $77.1 \%$ at rest). The high levels of subject satisfaction reported in these studies support investigator assessments of treatment success with incobotulinumtoxinA. High levels of subject satisfaction were also reported in a recent large retrospective analysis of incobotulinumtoxinA and onabotulinumtoxinA for treatment of wrinkles of the upper face in daily clinical practice. ${ }^{90}$ This study found no significant difference between incobotulinumtoxinA and onabotulinumtoxinA in subject or physician satisfaction with treatment.

\section{Conclusion}

IncobotulinumtoxinA has many benefits for the treatment of glabellar frown lines. It differs from other commercially available BoNT/A preparations in that, due to its specific purification process, incobotulinumtoxinA is free from complexing proteins and contains only active neurotoxin, thereby reducing the foreign protein load to a minimum and minimizing the risk of neutralizing antibody production. In practical terms, it has a long shelf-life, remaining stable without the need for refrigeration, and, due to its limited ability to spread, is a precise, localized treatment. Clinical trial data have demonstrated that incobotulinumtoxinA is an effective and well-tolerated treatment for glabellar frown lines at $20 \mathrm{U}$, with rapid onset, long duration of effect, and high subject satisfaction, and that a unit conversion ratio between incobotulinumtoxinA and onabotulinumtoxinA of $1: 1$ is appropriate.

\section{Acknowledgment}

Editorial assistance was provided by Ogilvy 4D, Oxford, UK, and funded by Merz Pharmaceuticals $\mathrm{GmbH}$.

\section{Disclosure}

Welf Prager has acted as a consultant and lecturer for Allergan Inc, Merz Pharmaceuticals GmbH, and Galderma Pharma SA.

\section{References}

1. Flynn TC, Carruthers A, Carruthers J, et al. Validated assessment scales for the upper face. Dermatol Surg. 2012;38(2 Spec No):309-319.

2. Friedman O. Changes associated with the aging face. Facial Plast Surg Clin North Am. 2005;13(3):371-380.

3. Fedok FG. The aging face. Facial Plast Surg. 1996;12(2):107-115.

4. Cox SE, Finn JC. Social implications of hyperdynamic facial lines and patient satisfaction outcomes. Int Ophthalmol Clin. 2005;45(3): 13-24.

5. Carruthers A, Kiene K, Carruthers J. Botulinum A exotoxin use in clinical dermatology. J Am Acad Dermatol. 1996;34(5 Pt 1):788-797.

6. Carruthers JA, Lowe NJ, Menter MA, et al. A multicenter, doubleblind, randomized, placebo-controlled study of the efficacy and safety of botulinum toxin type A in the treatment of glabellar lines. $\mathrm{J} \mathrm{Am} \mathrm{Acad}$ Dermatol. 2002;46(6):840-849.

7. Wollmer MA, de Boer C, Kalak N, et al. Facing depression with botulinum toxin: a randomized controlled trial. J Psychiatr Res. 2012;46(5): 574-581.

8. Sasaki GH. Comparison of results of wire subcision performed alone, with fills, and/or with adjacent surgical procedures. Aesthet Surg J. 2008;28(6):619-626.

9. De Cordier BC, de la Torre JI, Al-Hakeem MS, et al. Endoscopic forehead lift: review of technique, cases, and complications. Plast Reconstr Surg. 2002;110(6):1558-1568; discussion 1569-1570.

10. Hafezi F, Naghibzadeh B, Nouhi A, Naghibzadeh G. Eliminating frown lines with an endoscopic forehead lift procedure (corrugator muscle disinsertion). Aesthetic Plast Surg. 2011;35(4):516-521.

11. Mandel MA. Treatment of glabellar frown lines using silicone implants. Ann Plast Surg. 1991;27(2):110-114.

12. Brandt FS, Bellman B. Cosmetic use of botulinum A exotoxin for the aging neck. Dermatol Surg. 1998;24(11):1232-1234.

13. Carruthers JD, Carruthers JA. Treatment of glabellar frown lines with C. botulinum-A exotoxin. J Dermatol Surg Oncol. 1992;18(1):17-21.

14. Blugerman G, Schavelzon D, Anderhuber F, Martinez L, Chomyzsyn A. Corrugator supercilii muscle terminal nerve ablation using a novel thread technique for the treatment of hyperdynamic vertical glabellar furrows. J Drugs Dermatol. 2011;10(7):762-765.

15. Carruthers JD, Glogau RG, Blitzer A. Advances in facial rejuvenation: botulinum toxin type a, hyaluronic acid dermal fillers, and combination therapies - consensus recommendations. Plast Reconstr Surg. 2008;121(Suppl 5):5S-30S; quiz 31S-36S.

16. Cho SB, Lee SJ, Hwang YS, Lee KC, Oh SH. Radiofrequency-selective nerve ablation for glabellar frown lines in East Asian patients. Clin Exp Dermatol. 2009;34(7):e393-e394.

17. Kim JH, Jeong JW, Son D, et al. Percutaneous selective radiofrequency nerve ablation for glabellar frown lines. Aesthet Surg J. 2011;31(7): $747-755$.

18. Nahai FR. Update on radiofrequency ablation of the frontal branch to the corrugator muscles to reduce glabellar frown lines. Plast Reconstr Surg. 2010;125(5):208e.

19. Dreizen NG, Framm L. Sudden unilateral visual loss after autologous fat injection into the glabellar area. Am J Ophthalmol. 1989;107(1): 85-87. 
20. Teimourian B. Blindness following fat injections. Plast Reconstr Surg. 1988;82(2):361.

21. Stephan S, Wang TD. Botulinum toxin: clinical techniques, applications, and complications. Facial Plast Surg. 2011;27(6):529-539.

22. Prager W, Rappl T. Phase IV study comparing incobotulinumtoxinA and onabotulinumtoxinA using a 1:1.5 dose-conversion ratio for the treatment of glabellar frown lines. J Cosmet Dermatol. Epub 2012 Oct 2.

23. Beer KR, Boyd C, Patel RK, Bowen B, James SP, Brin MF. Rapid onset of response and patient-reported outcomes after onabotulinumtoxinA treatment of moderate-to-severe glabellar lines. J Drugs Dermatol. 2011;10(1):39-44.

24. Bocouture ${ }^{\circledR}$. Summary of product characteristics. Frankfurt am Main, Germany: Merz Pharmaceuticals GmbH; 2012.

25. Fedok FG. Advances in minimally invasive facial rejuvenation. Curr Opin Otolaryngol Head Neck Surg. 2008;16(4):359-368.

26. Goldman A, Wollina U. Facial rejuvenation for middle-aged women: a combined approach with minimally invasive procedures. Clin Interv Aging. 2010;5:293-299.

27. Azzalure ${ }^{\circledR}$. Summary of product characteristics. Berkshire, UK: Ipsen Ltd; 2010.

28. Raspaldo H, Baspeyras M, Bellity P, et al. Upper- and mid-face anti-aging treatment and prevention using onabotulinumtoxin $\mathrm{A}$ : the 2010 multidisciplinary French consensus - part 1. J Cosmet Dermatol. 2011;10(1):3-50.

29. Trindade De Almeida AR, Secco LC, Carruthers A. Handling botulinum toxins: an updated literature review. Dermatol Surg. 2011;37(11): 1553-1565.

30. Bakheit AM. The possible adverse effects of intramuscular botulinum toxin injections and their management. Curr Drug Saf. 2006;1(3): 271-279.

31. Carruthers A, Carruthers J, Cohen J. Dilution volume of botulinum toxin type A for the treatment of glabellar rhytides: does it matter? Dermatol Surg. 2007;33(1 Spec No):S97-S104.

32. Klein AW. Dilution and storage of botulinum toxin. Dermatol Surg. 1998;24(11):1179-1180.

33. Klein AW. Complications and adverse reactions with the use of botulinum toxin. Dis Mon. 2002;48(5):336-356.

34. Francisco GE. Botulinum toxin: dosing and dilution. Am J Phys Med Rehabil. 2004;83(Suppl 10):S30-S37.

35. Prager W, Zschocke I, Reich C, Brocatti L, Henning K, Steinkraus V. Does dilution have an impact on cosmetic results with BoNT/A? Complex-protein-free BoNT/A for treatment of glabella lines. Hautarzt. 2009;60(10):815-820.

36. Hankins CL, Strimling R, Rogers GS. Botulinum A toxin for glabellar wrinkles. Dose and response. Dermatol Surg. 1998;24(11): 1181-1183.

37. Vistabe $l^{\circledR}$. Summary of product characteristics. Irvine, CA: Allergan, Inc; 2010.

38. Carruthers J, Fagien S, Matarasso SL. Consensus recommendations on the use of botulinum toxin type a in facial aesthetics. Plast Reconstr Surg. 2004;114(Suppl 6):1S-22S.

39. Imhof M, Kühne U. A Phase III study of incobotulinumtoxinA in the treatment of glabellar frown lines. J Clin Aesthet Dermatol. 2011;4(10): $28-34$.

40. Trindade de Almeida AR, Martins da Costa Marques ER, Kadunc BV. Glabellar wrinkles: a pilot study of contraction patterns. Surg Cosmet Dermatol. 2010;2(1):23-28.

41. Carruthers JD, Lowe NJ, Menter MA, Gibson J, Eadie N. Double-blind, placebo-controlled study of the safety and efficacy of botulinum toxin type A for patients with glabellar lines. Plast Reconstr Surg. 2003;112(4):1089-1098.

42. Carruthers A, Carruthers J, Coleman III WP, et al. Multicentre, randomized, Phase III study of a single dose of incobotulinumtoxinA, free from complexing proteins, in the treatment of glabellar frown lines. Dermatol Surg. In press 2013.
43. Hanke CW, Narins RS, Brandt F, et al. A randomized, placebo-controlled, double blind Phase III trial investigating the efficacy and safety of incobotulinumtoxinA in the treatment of glabellar frown lines using a stringent composite endpoint. Dermatol Surg. In press 2013.

44. Rzany B, Flynn TC, Schlöbe A, Heinz M, Harrington L. Long-term results for incobotulinumtoxinA in the treatment of glabellar frown lines. Dermatol Surg. 2013;39:95-103.

45. Carruthers A, Carruthers J, Said S. Dose-ranging study of botulinum toxin type A in the treatment of glabellar rhytids in females. Dermatol Surg. 2005;31(4):414-422.

46. Grimes PE, Shabazz D. A four-month randomized, double-blind evaluation of the efficacy of botulinum toxin type A for the treatment of glabellar lines in women with skin types V and VI. Dermatol Surg. 2009;35(3):429-435; discussion 435-426.

47. Moers-Carpi M, Fulford-Smith A, Tan K. A multicenter, randomized, double-blind study to evaluate the efficacy of onabotulinumtoxina (20 units) in the treatment of glabellar lines, when compared to incoboulinumtoxina (30 units). J Am Acad Dermatol. 2012;66(481):AB20.

48. Sattler G, Callander MJ, Grablowitz D, et al. Noninferiority of incobotulinumtoxinA, free from complexing proteins, compared with another botulinum toxin type $\mathrm{A}$ in the treatment of glabellar frown lines. Dermatol Surg. 2010;36 (Suppl 4):2146-2154.

49. Dressler D, Benecke R. Pharmacology of therapeutic botulinum toxin preparations. Disabil Rehabil. 2007;29(23):1761-1768.

50. Hackett R, Kam PC. Botulinum toxin: pharmacology and clinical developments: a literature review. Med Chem. 2007;3(4):333-345.

51. Rosales RL, Bigalke H, Dressler D. Pharmacology of botulinum toxin: differences between type A preparations. Eur J Neurol. 2006;13 (Suppl 1):2-10.

52. Dong M, Yeh F, Tepp WH, et al. SV2 is the protein receptor for botulinum neurotoxin A. Science. 2006;312(5773):592-596.

53. Hambleton P. Clostridium botulinum toxins: a general review of involvement in disease, structure, mode of action and preparation for clinical use. J Neurol. 1992;239(1):16-20.

54. Jost WH, Blumel J, Grafe S. Botulinum neurotoxin type A free of complexing proteins (XEOMIN) in focal dystonia. Drugs. 2007;67(5): 669-683.

55. Frevert J, Dressler D. Complexing proteins in botulinum toxin type A drugs: a help or a hindrance? Biologics. 2010;4:325-332.

56. Eisele K-H, Taylor H. Dissociation of the $900 \mathrm{kDa}$ neurotoxin complex from C.botulinum under physiological conditions. Toxicon. 2008;51 (Suppl 1):10 (Abstr 28).

57. Kerscher M, Roll S, Becker A, Wigger-Alberti W. Comparison of the spread of three botulinum toxin type A preparations. Arch Dermatol Res. 2012;304(2):155-161.

58. Eisele K-H, Fink K, Vey M, Taylor HV. Studies on the dissociation of botulinum neurotoxin type A complexes. Toxicon. 2011;57(4): $555-565$.

59. Chen F, Kuziemko GM, Stevens RC. Biophysical characterization of the stability of the 150-kilodalton botulinum toxin, the nontoxic component, and the 900-kilodalton botulinum toxin complex species. Infect Immun. 1998;66(6):2420-2425.

60. Grein SMG, Fink K. Stability of botulinum neurotoxin type A, devoid of complexing proteins. The Botulinum Journal. 2011;2(1):49-58.

61. Frevert J. Content of botulinum neurotoxin in $\operatorname{Botox}^{\circledR} / V^{\text {Vistabe }}{ }^{\circledR}$, Dysport $^{\circledR} /$ Azzalure $^{\circledR}$, and Xeomin ${ }^{\circledR} /$ Bocouture $^{\circledR}$. Drugs R D. 2010;10(2): $67-73$.

62. Carruthers A, Carruthers J. Botulinum toxin products overview. Skin Therapy Lett. 2008;13(6):1-4.

63. Borodic G. Immunologic resistance after repeated botulinum toxin type A Injections for facial rhytides. Ophthal Plast Reconstr Surg. 2006;22(3):239-240.

64. Dressler D, Wohlfahrt K, Meyer-Rogge E, Wiest L, Bigalke H. Antibody-induced failure of botulinum toxin a therapy in cosmetic indications. Dermatol Surg. 2010;36(Suppl 4):2182-2187. 
65. Lee S-K. Antibody-induced failure of botulinum toxin type A therapy in a patient with masseteric hypertrophy. Dermatol Surg. 2007;33(1 Spec No):S105-S110.

66. Stengel G, Bee EK. Antibody-induced secondary treatment failure in a patient treated with botulinum toxin type A for glabellar frown lines. Clin Interv Aging. 2011;6:281-284.

67. Blümel J, Frevert J, Schwaier A. Comparative antigenicity of three preparations on boutlinum neurotoxin A in the rabbit. Neurotox Res. 2006;9:238.

68. Jimenez-Shahed J. A new treatment for focal dystonias: incobotulinumtoxinA $\left(\mathrm{Xeomin}^{\circledR}\right)$, a botulinum neurotoxin type A free from complexing proteins. Neuropsychiatr Dis Treat. 2012;8:13-25.

69. Benecke R. Xeomin in the treatment of cervical dystonia. Eur J Neurol. 2009;16 (Suppl 2):6-10.

70. Bigalke H, Frevert J. Botulinum toxin A: dose and immune response. Int J Rehabil Res. 2012;35(2):93.

71. Jankovic J, Vuong KD, Ahsan J. Comparison of efficacy and immunogenicity of original versus current botulinum toxin in cervical dystonia. Neurology. 2003;60(7):1186-1188.

72. Panjwani N, O'Keeffe R, Pickett A. Biochemical, functional and potency characteristics of type A botulinum toxin in clinical use. Botulinum J. 2008;1(1):153-166.

73. Dressler D, Mander G, Fink K. Measuring the potency labelling of onabotulinumtoxinA $\left(\right.$ Botox $\left.^{\mathbb{R}}\right)$ and incobotulinumtoxinA $\left(\mathrm{Xeomin}^{\sqrt{\mathbb{R}}}\right)$ in an LD50 assay. J Neural Transm. 2012;119(1):13-15.

74. Sattler G, Callander M, Grablowitz D, et al. Noninferiority of incobotulinumtoxinA, free from complexing proteins, compared with another botulinum toxin type $\mathrm{A}$ in the treatment of glabellar frown lines. Dermatol Surg. 2010;36(S4):2146-2154.

75. de Almeida AT, De Boulle K. Diffusion characteristics of botulinum neurotoxin products and their clinical significance in cosmetic applications. J Cosmet Laser Ther. 2007;9 (Suppl 1):17-22.

76. Hexsel D, Dal'Forno T, Hexsel C, Do Prado DZ, Lima MM. A randomized pilot study comparing the action halos of two commercial preparations of botulinum toxin type A. Dermatol Surg. 2008;34(1):52-59.

77. Trindade de Almeida AR, Marques E, de Almeida J, Cunha T, Boraso R. Pilot study comparing the diffusion of two formulations of botulinum toxin type A in patients with forehead hyperhidrosis. Dermatol Surg. 2007;33(1 Spec No):S37-S43.

78. Snapinn SM. Noninferiority trials. Curr Control Trials Cardiovasc Med. 2000;1(1):19-21.

79. Pinto VF. Non-inferiority versus equivalence clinical trials in assessing biological products. Sao Paulo Med J. 2011;129(3):183-184.
80. Rappl T, Wiedner M, Kranzlbinder B, Haas F. Is there a difference in persistence, efficiency and efficacy of 3 BoNT/A-containing products? A double-blind, randomised study. Presented at the International Master Course on Aging Skin Asia Congress; 2010; Hong Kong, China.

81. Merz Pharmaceuticals GmbH. IncobotulinumtoxinA (Xeomin) versus placebo in the treatment of glabellar frown lines. http://clinicaltrials. gov/ct2/show/NCT00430963?term=NCT00430963\&rank=1. Accessed August 31, 2012.

82. Merz Pharmaceuticals GmbH. Finding of optimal dose for NT 201 in the treatment of glabellar frown lines. http://clinicaltrials.gov/ct2/show/ NCT00430586?term $=$ NCT00430586\&rank=1. Accessed August 31, 2012.

83. Schleyer V, Berneburg M. Efficacy and safety of botulinum neurotoxin type A (Xeomin) in the treatment of facial expression frown lines. Kosmetische Medizin - ENGLISH Abstract. 2008.

84. Schlessinger J, Monheit G, Kane MA, Mendelsohn N. Time to onset of response of abobotulinumtoxina in the treatment of glabellar lines: a subset analysis of phase 3 clinical trials of a new botulinum toxin type A. Dermatol Surg. 2011;37(10):1434-1442.

85. Prager W, Bee EK, Havermann I, Zschocke I. Onset, longevity and subject satisfaction with incobotulinumtoxinA for the treatment of glabellar frown lines: a single-arm, prospective clinical study. Clin Interv Aging. In press 2013.

86. Dessy LA, Fallico N, Mazzocchi M, Scuderi N. Botulinum toxin for glabellar lines: a review of the efficacy and safety of currently available products. Am J Clin Dermatol. 2011;12(6):377-388.

87. Jandhyala R. Relative potency of incobotulinumtoxinA vs onabotulinumtoxinA a meta-analysis of key evidence. J Drugs Dermatol. 2012; 11(6):731-736.

88. Marchetti A, Magar R, Findley L, et al. Retrospective evaluation of the dose of Dysport and BOTOX in the management of cervical dystonia and blepharospasm: the REAL DOSE study. Mov Disord. 2005;20(8): 937-944.

89. Karsai S, Raulin C. Current evidence on the unit equivalence of different botulinum neurotoxin A formulations and recommendations for clinical practice in dermatology. Dermatol Surg. 2009;35(1): $1-8$.

90. Prager W, Huber-Vorländer J, Taufig AZ, et al. Botulinum toxin type A treatment to the upper face: a retrospective analysis of daily practice. Clin Cosmetic Invest Dermatol. 2012;5:53-58.

91. Bakshi E, Hartstein ME. Compositional differences among commercially available botulinum toxin type A. Curr Opin Ophthalmol. 2011; 22(5):407-412.
Clinical Pharmacology: Advances and Applications

\section{Publish your work in this journal}

Clinical Pharmacology: Advances and Applications is an international, peer-reviewed, open access journal publishing original research, reports, reviews and commentaries on all areas of drug experience in humans The manuscript management system is completely online and includes a very quick and fair peer-review system, which is all easy to use.

\section{Dovepress}

Visit http://www.dovepress.com/testimonials.php to read real quotes from published authors. 